\title{
ANTICORPOS CONTRA O HERPESVÍRUS BOVINO TIPO 1, VÍRUS DA DIARREIA VIRAL BOVINA E VÍRUS DA LEUCOSE ENZOÓTICA BOVINA NA REGIÃO DA CAMPANHA DO ESTADO DO RIO GRANDE DO SUL
}

\begin{abstract}
PIOVESAN, Matheus ${ }^{1}$ FERNANDES, Maureen Hoch Vieira ${ }^{1}$ CORRÊA, Rayra Almeida ${ }^{1}$ PRADO, Márcia Helena Jorgens ${ }^{1}$ CAMARGO, Aline Dias ${ }^{1}$ RODRIGUES, Paulo Ricardo Centeno ${ }^{2}$

${ }^{1}$ Bolsista de iniciação científica do Laboratório de Virologia e Imunologia da UFPEL, ${ }^{2}$ Medico Veterinário, Mestre, Laboratório de Virologia e Imunologia da UFPEL.

RESUMO

fundamental para o manejo sanitário dos rebanhos bovinos de leite e corte o suporte de laboratórios especializados como uma ferramenta auxiliar no diagnóstico preciso de doenças infecciosas. O objetivo deste trabalho foi apresentar os resultados dos exames sorológicos realizados pelo Laboratório de Virologia e Imunologia da Faculdade de Veterinária da Universidade Federal de Pelotas entre os anos de 2009 e 2012, na área de bovinocultura de corte e leite. Um total de 6092 amostras de soro bovino foram submetidas à técnica de soroneutralização para a detecção de anticorpos específicos contra o herpesvírus bovino tipo 1 (BoHV-1) e o vírus da Diarréia Viral Bovina (BVDV), e à técnica de imunodifusão em gel de ágar para detecção de anticorpos específicos contra o vírus da Leucose Enzoótica Bovina (BLV). Os resultados demonstraram que 52,9\%, 85,4\% e 41,3\% das amostras testadas apresentaram anticorpos específicos contra o BoHV-1, BVDV e o BLV, respectivamente. Os Laboratórios Regionais de Diagnóstico são essenciais para o conhecimento da situação epidemiológica dos rebanhos e diagnóstico preciso de enfermidades infecciosas de etiologia viral.
\end{abstract}

Palavras-chave: Bovinocultura. Doenças virais. IBR/IPV. BVD. EBL. 


\section{INTRODUÇÃO}

O diagnóstico laboratorial das doenças infectocontagiosas é essencial para a implementação de programas sanitários, especialmente nas áreas de bovinocultura de leite e corte. $\mathrm{O}$ Laboratório de Virologia e Imunologia (Labvir) da Faculdade de Veterinária da Universidade Federal de Pelotas (UFPEL), entre outras atividades, realiza rotineiramente exames diagnósticos para as seguintes enfermidades que acometem bovinos: Rinotraqueíte Infecciosa Bovina/Vulvovaginite Pustular Infecciosa, Diarreia Viral Bovina e Leucose Enzoótica Bovina.

A Rinotraqueíte Infecciosa Bovina/Vulvovaginite Pustular Infecciosa (IBR/IPV) é uma doença de distribuição mundial causada pelo herpesvírus bovino tipo 1 (BoHV-1). No estado do Rio Grande do Sul, a enfermidade foi diagnosticada pela primeira vez em janeiro de 1987, na região do Taim, município de Rio Grande, acometendo bovinos. O diagnóstico foi confirmado pelo isolamento do BoHV-1 em cultivo celular (HALFEN; VIDOR, 2001). O vírus pertence à família Herpesviridae, subfamília Alphaherpesvirinae, gênero Varicellovirus (ROIZMANN; PELLETT, 2007; THIRY et al., 2007). Como os outros membros da família Herpesviridae, também estabelece infecção latente nos neurônios dos gânglios nervosos regionais do hospedeiro. Deste modo, animais infectados, mesmo com infecção inaparente, tornam-se portadores para o resto da vida (FRANCO; ROEHE, 2012; HALFEN; VIDOR, 2001). As principais portas de entrada do vírus são as superfícies mucosas do trato respiratório e genital (URBINA et al., 2005). A forma respiratória se caracteriza por febre, anorexia, conjuntivite, hiperpnéia, dispnéia e descarga nasal. A forma genital caracteriza-se por lesões na mucosa da vulva e vagina e do prepúcio e pênis. $O$ aborto é mais frequente no terço final da gestação e pode ocorrer em qualquer das formas de infecção pelo BoHV-1, inclusive as subclínicas (HALFEN; VIDOR, 2001; RADOSTITS et al., 2002). Vacas infectadas pelo BoHV-1 podem gerar bezerros fracos, debilitados e com malformação congênita (ALY et al., 2003). Nos machos, a doença é conhecida como Balanopostite Pustular Infecciosa (IPB), causando hiperemia, edema da mucosa, com pontos hemorrágicos e pequenas pústulas na região do pênis e prepúcio (FAUQUET et al., 2004). 
O diagnóstico da infecção pelo BoHV-1 é confirmado através de testes laboratoriais, porém o histórico sanitário e reprodutivo do rebanho devem ser levados em consideração (TAKIUCHI et al., 2005). O isolamento do vírus em cultivo de células de origem bovina é o melhor método de diagnóstico, podendo ser identificado pelas técnicas de imunofluorescência ou virusneutralização. A soroneutralização e o ensaio imunoenzimático (ELISA) são utilizados na rotina para deteç̧ão de anticorpos contra o BoHV-1 (BARBOSA et al., 2005; JUNQUEIRA et al., 2006; QUINCOZES, 2005; ROCHA et al., 2001). A vacinação para IBR/IPV é utilizada para o controle da enfermidade, embora não impeça a infecção pelo vírus, diminui consideravelmente a incidência e as manifestações clínicas (HALFEN; VIDOR, 2001).

A Diarreia Viral Bovina (BVD) é uma enfermidade viral responsável por graves prejuízos econômicos à bovinocultura de leite e corte, sendo relatada sua presença em todos os países em que essas atividades alcançam relevância (DIAS; SAMARA, 2003). O vírus causador da Diarréia Viral Bovina (BVDV) pertence à família Flaviviridae, gênero Pestivirus; sua transmissão pode ocorrer por contato direto, indireto ou de modo iatrogênico (agulhas, material cirúrgico contaminado, luvas de palpação, tatuadores, aplicadores de brinco) (RIDPATH et al., 2012; SCHUCH, 2001). As manifestações clínicas da infeç̧ão podem ser agrupadas em quatro formas principais: doença aguda leve (gastroentérica, respiratória), doença aguda severa (gastroentérica, respiratória e hemorrágica), doença das mucosas (DM) e BVD crônica, entretanto, os prejuízos principais são de ordem reprodutiva (RIDPATH et al., 2012).

A infecção de fêmeas gestantes pelo BVDV pode resultar em reabsorção embrionária (com retorno ao cio), abortos, mumificação fetal, natimortos, nascimentos de bezerros fracos e inviáveis, que morrem em seguida ou apresentam crescimento retardado; ou o nascimento de animais persistentemente infectados (PI). Em geral, abortos em qualquer fase da gestação podem ser associados a esse vírus (RIDPATH et al., 2012; SCHUCH, 2001). Para identificação viral são utilizadas diferentes técnicas sorológicas como imunofluorescência, imunoperoxidase e ensaio imunoenzimático (ELISA). Em relação à detecção de anticorpos específicos, uma das técnicas mais utilizadas é a soroneutralização (PILZ et al., 2005). O controle da enfermidade é baseado na eliminação de animais PI e monitoramento do 
ingresso de animais e sêmen, assim como a vacinação com cepas regionais ou com vacinas produzidas com diferentes cepas do vírus (SCHUCH, 2001).

A Leucose Enzoótica Bovina (EBL) é uma enfermidade viral que se apresenta sob duas formas: o linfossarcoma, a doença neoplásica mais frequente do gado leiteiro, e a linfocitose persistente, um aumento benigno no número de linfócitos circulantes (BRAGA; VAN DER LAAN, 2001). A enfermidade é causada por um vírus RNA tumoral pertencente à família Retroviridae, gênero Deltaretrovirus. O vírus da Leucose Enzoótica Bovina (BLV) possui distribuição mundial, com exceção de alguns países europeus que erradicaram a infecção a partir da década de 1980 (BARROS FILHO et al., 2010). O principal meio de transmissão é de modo horizontal; como outros retrovírus, apresenta baixa transmissibilidade. Como o vírus está presente no sangue dos animais infectados, pode ser transmitido por procedimentos que envolvam a transferência de células sanguíneas entre os animais (palpação retal com a mesma luva obstétrica, injeções sem a troca da agulha, uso de tatuadoras, descornadores, brincadores, instrumentos cirúrgicos contaminados). Os animais infectados tornam-se portadores permanentes e albergam o vírus no sangue, especialmente nos linfócitos B (RAVAZZOLO; COSTA, 2012).

No Brasil, a doença está presente em todos os estados, sendo mais prevalente em bovinos adultos de raças leiteiras. A forma tumoral ocorre em animais entre quatro e oito anos de idade (BRAGA; VAN DER LAAN, 2001; CHAMIZO, 2005). Entre os animais infectados, em torno de $30 \%$ desenvolvem linfocitose persistente, sem manifestar sinais clínicos. De modo geral, entre 1 e $5 \%$ dos animais infectados irão desenvolver a forma tumoral (CAMARGOS et al., 2004; RAVAZZOLO; COSTA, 2012).

Os sinais clínicos dependem dos órgãos ou sistemas atingidos pelos tumores linfoides, em geral os animais apresentam adenomegalia, anorexia, queda na produção e perda de peso que leva à caquexia e decúbito (RADOSTITS et al., 2002). Conforme Braga e Van Der Laan (2001), transtornos como infertilidade e queda na produção de leite, estão relacionados com a infecção pelo BLV.

O diagnóstico da forma tumoral se baseia nos sinais clínicos e deve ser confirmado por exames histopatológicos. A infecção pode ser diagnosticada por testes sorológicos. O teste 
de imunodifusão em gel de ágar (IDGA) é considerado o teste oficial para detecção de anticorpos anti-BLV na maioria dos países (RAVAZZOLO; COSTA, 2012).

Como não existem vacinas ou tratamentos eficazes, o controle baseia-se em medidas que dificultam a disseminação do vírus. Os programas de erradicação são utilizados em áreas de baixa prevalência. No Brasil, recomenda-se a segregação dos animais soropositivos e a adoção de práticas de manejo que reduzam a transmissão iatrogênica e horizontal do BLV (BRAGA et al., 1998; BRAGA; VAN DER LAAN, 2001; LEUZZI JUNIOR et al., 2001).

Este trabalho tem como objetivo apresentar os resultados de um estudo retrospectivo com base nos testes sorológicos realizados pelo Labvir durante o período de 2009 a 2012 contra o herpesvírus bovino tipo 1 (BoHV-1), vírus da Diarreia Viral Bovina (BVDV) e o vírus da Leucose Enzoótica Bovina (BLV) em rebanhos da região da campanha do estado do Rio Grande do Sul.

\section{MATERIAL E MÉTODOS}

Foram colhidas amostras de sangue de 3377 bovinos durante o período de 2009 a 2012, de raças de corte e leite provenientes de 157 propriedades rurais da região da campanha do estado do Rio Grande do Sul. As amostras foram colhidas por punção da veia jugular externa com agulhas descartáveis, armazenadas em tubos esterilizados sem anticoagulante e enviadas sob refrigeração ao laboratório. Após a centrifugação (2000 rpm durante 15 min.) os soros obtidos foram armazenados em microtubos tipo Eppendorf, colocados em um banho-maria a $56{ }^{\circ} \mathrm{C}$ por 30 minutos para inativação do sistema complemento e mantidos a $-20^{\circ} \mathrm{C}$ para posterior processamento.

A determinação dos títulos de anticorpos contra o BoHV e o BVDV foram obtidos através da técnica de soroneutralização (SN) conforme descrita por Fischer et al. (2007). Para o diagnóstico da Leucose foi utilizada a prova de imunodifusão em gel de ágar (IDGA) segundo a metodologia padronizada por Miller e Van Der Maaten (1976).

Entre os anos de 2009 e 2012 foram processados 6092 exames, sendo 2794 para BoHV, 2763 para BVDV e 535 exames para BLV. 


\section{RESULTADOS E DISCUSSÃO}

O número de propriedades rurais e animais testados para BoHV-1, BVDV e BLV, bem como os resultados referentes aos exames sorológicos realizados entre os anos de 2009 e 2012 no Labvir/UFPEL estão apresentados nas Tabelas 1 e 2, respectivamente.

Tabela 1 - Propriedades rurais avaliadas, bovinos examinados e exames realizados no Laboratório de Virologia e Imunologia da Faculdade de Veterinária da UFPEL entre os anos de 2009 e 2012.

\begin{tabular}{cccc}
\hline Ano & Propriedades rurais (no) & Bovinos (no) & Exames realizados (no) \\
\hline $\mathbf{2 0 0 9}$ & 49 & 1059 & 1962 \\
$\mathbf{2 0 1 0}$ & 40 & 714 & 1281 \\
$\mathbf{2 0 1 1}$ & 33 & 865 & 1573 \\
$\mathbf{2 0 1 2}$ & 35 & 739 & 1276 \\
\hline
\end{tabular}

Tabela 2 - Resultados referentes aos exames sorológicos para BoHV-1, BVDV e BLV realizados entre os anos de 2009 e 2012 no Laboratório de Virologia e Imunologia da Faculdade de Veterinária da UFPEL.

\begin{tabular}{c|cc|cc|cc|cc}
\hline & $\mathbf{2 0 0 9}$ & $\%$ & $\mathbf{2 0 1 0}$ & $\%$ & $\mathbf{2 0 1 1}$ & $\%$ & $\mathbf{2 0 1 2}$ & $\%$ \\
\hline BoHV-1 & & & & & & & & \\
Positivos & 610 & 63,2 & 445 & 74 & 316 & 51,1 & 283 & 46,5 \\
Negativos & 355 & 36,8 & 156 & 26 & 303 & 48,9 & 326 & 53,5 \\
Total & 965 & 100 & 601 & 100 & 619 & 100 & 609 & 100 \\
\hline BVDV & & & & & & & & \\
Positivos & 861 & 87,9 & 553 & 93,9 & 541 & 87,7 & 404 & 70,0 \\
Negativos & 119 & 12,1 & 36 & 6,1 & 76 & 12,3 & 173 & 30,0 \\
Total & 980 & 100 & 589 & 100 & 617 & 100 & 577 & 100 \\
\hline BLV & & & & & & & & \\
Positivos & 7 & 41,2 & 26 & 28,6 & 165 & 49,0 & 23 & 25,5 \\
Negativos & 10 & 58,8 & 65 & 71,4 & 172 & 51,0 & 67 & 74,5 \\
Total & 17 & 100 & 91 & 100 & 337 & 100 & 90 & 100 \\
\hline
\end{tabular}

Os animais avaliados para a presença de anticorpos específicos contra o BoHV e BVDV eram provenientes de propriedades rurais que utilizam ou não vacinas contra esses agentes. Como a SN para BoHV e BVDV não permite a discriminação sorológica entre anticorpos vacinais e anticorpos resultantes de uma infecção natural por esses agentes, nem todos os animais positivos podem ser considerados infectados. Diferente do que acontece para EBL, 
em que animais positivos são considerados infectados pelo vírus, uma vez que não há vacinas contra essa enfermidade.

Um estudo sobre a soroprevalência de herpesvírus bovino tipo 1 e/ou tipo 5 no estado do Rio Grande de Sul, realizado por Holz et al. (2009), examinou 2200 soros provenientes de 390 propriedades pertencentes a 158 municípios, representativos das 7 mesorregiões do estado, e identificou uma prevalência de $29,2 \%$ (642/2200) de soropositivos em $57,7 \%$ das propriedades (225/390). A prevalência de 59,2\% encontrada na presente retrospectiva reflete a pesquisa de anticorpos contra BoHV em animais vacinados e não-vacinados.

Quincozes et al. (2007) avaliaram a prevalência da infecção pelo BVDV em dois municípios da região da campanha do estado do Rio Grande do Sul (Santa Vitória do Palmar e Chuí). Das 85 propriedades rurais estudadas, 70 (82,35\%) apresentaram bovinos sorologicamente positivos. Das 1734 amostras de sangue processadas, 1150 (66,32\%) mostraram-se positivas. Neste trabalho identificou-se $85,4 \%$ de animais sorologicamente positivos para BVD, valores obtidos de animais vacinados e não-vacinados.

No Brasil o percentual de animais soropositivos para EBL varia consideravelmente entre os vários estados da Federação, no estado do Rio Grande do Sul, Moraes et al. (1996), avaliaram 39799 amostras de soro bovino de raças leiteiras, provenientes de 4200 propriedades rurais de 172 municípios e encontraram 9,2\% (3645/39799) de animais positivos. O percentual de animais soropositivos para EBL identificados no Labvir foi de 41,3\%. Esse valor elevado poderia ser explicado pelo envio de amostras, geralmente, de rebanhos contendo animais suspeitos e/ou com sintomatologia clínica da enfermidade.

\section{CONCLUSÃO}

A prevalência variável, porém relevante, dessas três enfermidades virais em nosso país, demonstra a necessidade do estabelecimento de uma política de defesa sanitária específica visando o controle e a redução dos prejuízos causados à produtividade dos rebanhos bovinos de leite e corte. Para tanto, uma ferramenta que permita a diferenciação entre anticorpos vacinais e resultantes de infecção é fundamental para o controle e eventual 
erradicação da IBR/IPV e BVD. No caso da EBL uma política sanitária que impeça e/ou minimize a contaminação por via iatrogênica é um aspecto fundamental para o controle dessa doença.

Neste contexto, é essencial a utilização dos serviços de diagnóstico oferecidos pelos Laboratórios Regionais para a identificação precisa dos problemas sanitários, além do estabelecimento de medidas de controle, a médio e longo prazo, em conjunto com os órgãos oficiais de Defesa Agropecuária.

\section{ANTIBODIES AGAINST BOVINE HERPESVIRUS TYPE-1, BOVINE VIRAL DIARRHEA VIRUS AND BOVINE LEUKOSIS VIRUS IN SOUTHERN RIO GRANDE DO SUL STATE, BRAZIL}

\section{ABSTRACT}

The assistance of specialized laboratories is essential for the precise diagnosis of infectious diseases in cattle. The objective of this study was to report the results of serological tests performed by the Laboratory of Virology and Immunology, Faculty of Veterinary Medicine of the Universidade Federal de Pelotas between 2009 and 2012. A total of 6092 bovine serum samples collected from different herds were submitted to virusneutralization test (VNT) and/or agar gel immunodiffusion (AGID), for the detection of antibodies against bovine herpesvirus type-1 (BoHV-1), bovine viral diarrhea virus (BVDV) and bovine leukosis virus (BLV). The results showed that $52.9 \%, 85.4 \%$ and $41.3 \%$ of the samples had specific antibodies against BoHV-1, BVDV and BLV, respectively. These results emphasize the importance of regional diagnostic laboratories for the knowledge of epidemiological situation of herds as well as for the accurate diagnosis of viral diseases.

Keywords: Cattle. Viral diseases. IBR/IPV. BVD. EBL. 


\title{
ANTICUERPOS CONTRA EL HERPESVIRUS BOVINO DE TIPO 1, VIRUS DE LA DIARREA VIRAL BOVINA Y VIRUS DE LA LEUCOSIS ENZOÓTICA BOVINA EN LA REGIÓN DE LA CAMPAÑA DEL ESTADO DE RIO GRANDE DO SUL, BRASIL
}

\section{RESUMEN}

\begin{abstract}
$\mathrm{E}$ s esencial para la gestión de la salud de los rebaños de ganado de leche y carne el apoyo de los laboratorios especializados como herramienta auxiliar en el diagnóstico preciso de las enfermedades infecciosas. El objetivo de este trabajo es presentar los resultados de las pruebas serológicas realizadas por el Laboratorio de Virología e Inmunología de la Facultad de Medicina Veterinaria de la Universidad Federal de Pelotas, entre los años 2009 y 2012 en el área de ganado de carne y leche. Un total de 6092 muestras de suero se sometieron a la prueba de neutralización del virus para la detección de anticuerpos específicos frente al herpesvirus bovino de tipo 1 (BoHV-1) y el virus de la Diarrea Viral Bovina (BVDV), y de inmunodifusión en gel de agar para la detección de anticuerpos específicos contra el virus de la Leucosis Enzoótica Bovina (BLV). Los resultados mostraron que $52,9 \%, 85,4 \%$ y $41,3 \%$ de las muestras analizadas mostraron anticuerpos específicos contra el BoHV-1, BVDV y BLV, respectivamente. Los laboratorios de diagnóstico regionales son esenciales para el conocimiento de la situación epidemiológica de los rebaños y el diagnóstico preciso de las enfermedades infecciosas de etiología viral.
\end{abstract}

Palabras clave: Bovinocultura. Enfermedades virales. IBR/IPV. BVD. EBL.

\section{REFERÊNCIAS}

ALY, N. M.; SHEHAB, G. G.; ABD EI-RAHIM, I. H. A. Bovine viral diarrhea, bovine herpesvirus and parainfluenza-3 virus infection in three cattle herds in Egypt in 2000. Revue scientifique et technique (International Office of Epizootics), v. 22, n. 3, p. 879-892, 2003.

BARBOSA, A. C. V. C.; BRITO, W. M. E. D.; ALFAIA, B. T. Soroprevalência e fatores de risco para a infecção pelo herpesvírus bovino tipo 1 (BHV-1) no Estado de Goiás, Brasil. Ciência Rural, v. 35, n. 6, p. 1368-1373, 2005.

BARROS FILHO, I. R.; GUIMARÃES, A. K.; SPONCHIADO, D.; KRÜGER, E. R.; WAMMES, E. V.; OLHOFF, R. D.; DORNBUSCH, P. T.; BIONDO, A. W. Soroprevalência de anticorpos para o vírus da leucose enzoótica em bovinos criados na região metropolitana de Curitiba, Paraná.

Revista Arquivos do Instituto Biológico, São Paulo, v. 77, p. 511-515, 2010.

BRAGA, F. M.; VAN DER LAAN, C. W.; SCHUCH, L. F.; HALFEN, D. C. Infecção pelo vírus da leucose enzoótica bovina (BLV). Ciência Rural, v. 28, n. 1, p. 163-172, 1998. 
BRAGA, F. M.; VAN DER LAAN, C. W. Leucose Enzoótica Bovina. In: RIET-CORREA, F.; SCHILD, A. L.; MENDEZ, M. D. C.; LEMOS, R. A. A. Doenças de Ruminantes e Equinos. São Paulo: Varela, 2001.

CAMARGOS, M. F.; REIS, J. K. P.; LEITE, R. C. Bovine Leukemia. Virus Reviews \& Research, v. 9, n. 1, p. 44-59, 2004.

CHAMIZO, E. G. Leucosis Bovina Enzootica: Revisión. Revista Electrónica de Veterinaria, v. VI, n. 7, 2005. Disponível em: http://www.redalyc.org/articulo.oa?id=63612652016. Acesso em: 20 de jun. 2013.

DIAS, F. C.; SAMARA, S. I. Detecção de anticorpos contra o vírus da diarréia viral bovina no soro sangüíneo, no leite individual e no leite de conjunto em tanque de expansão de rebanhos não vacinados. Brazilian Journal of Veterinary Research and Animal Science, São Paulo, v. 40, n. 3, p. 161-168, 2003.

FAUQUET, C. M.; MAYO M. A.; MANILOFF, J.; DESSELBERGER, U.; BALL, L. A. Virus Taxonomy: The Eighth Report of the International Committee on Taxonomy of Viruses. San Diego: Academic Press, 2004.

FISCHER, G.; CONCEIÇÃO, F. R.; LEITE, F. P. L.; DUMMER, L. A.; VARGAS, G. D.; HÜBNER, S. O.; et al. Immunomodulation produced by a green propolis extract on humoral and cellular responses of mice immunized with SuHV-1. Vaccine, n. 25, p. 1250-1256, 2007.

FRANCO, A. C.; ROEHE, P. M. Herpesviridae. In: FLORES, E. F (Org.) Virologia Veterinária. Santa Maria: Ed. da UFSM, 2012.

HALFEN, D. C.; VIDOR, T. In: RIET-CORREA, F.; SCHILD, A. L.; MENDEZ, M. D. C.; LEMOS, R. A. A. Doenças de Ruminantes e Equinos. São Paulo: Varela, 2001.

HOLZ, C. L.; CIBULSKI, S. P.; TEIXEIRA, T. F.; BATISTA, H. B. C. R.; CAMPOS, F. S.; SILVA, R. J.; VARELA, A. P. M.; CENCI, A.; FRANCO, A. C.; ROEHE, P. M. Soroprevalência de herpesvírus bovinos tipos 1 e/ou 5 no Estado do Rio Grande do Sul. Pesquisa Veterinária Brasileira, $v$. 29, n. 9, p. 767-773, 2009.

JUNQUEIRA, J. R. C.; FREITAS, J. C.; ALFIERI, A. F.; ALFIERI, A. A. Avaliação do desempenho reprodutivo de um rebanho bovino de corte naturalmente infectado com o BoHV-1, BVDV e Leptospira hardjo. Ciências Agrárias, v. 27, n. 3, p. 471-480, 2006.

LEUZZI JUNIOR, L. A.; ALFIERI, A. F.; ALFIERI, A. A. Leucose enzoótica bovina e vírus da leucemia bovina. Semina: Ciências Agrárias, Londrina, v. 22, n. 2, p. 211-221, jul./dez. 2001.

MILLER, J. M.; VAN DER MATTEN, M. J. Sorologic detection of Bovine Leukemia Virus Infection. Veterinary Microbiology, v. 31, p. 47-55, 1976. 
MORAES, M. P.; WEIBLEN, R.; FLORES, E. F.; OLIVEIRA, J. C. D.; REBELATTO, M. C.; ZANINI, M.; RABUSKE, M. HÜBNER, S. O.; PEREIRA, N. M. Levantamento sorológico da infecção pelo vírus da leucose bovina nos rebanhos leiteiros do estado do Rio Grande do Sul, Brasil. Ciência Rural, Santa Maria, v. 26, n. 2, p. 257-262, 1996.

PILZ, D.; ALFIERI, A. F.; ALFIERI, A. A. Comparação de diferentes protocolos para detecção do vírus da diarréia viral bovina por RT-PCR em grupos de sangue total e de soro sangüíneo, artificialmente contaminados. Ciências Agrárias, v. 26, n. 2, p. 219-228, 2005.

QUINCOZES, C. G. Prevalência e fatores de risco associados às infecções pelos herpesvírus bovino tipo 1 e 5 (BHV-1 e 5) e pelo vírus da diarréia viral bovina (BVDV) nos rebanhos dos municípios de Santa Vitória do Palmar e Chuí. Pelotas: UFPEL, 2005. Dissertação (Mestrado em Ciências). Universidade Federal de Pelotas, 2005.

QUINCOZES, C. G.; FISCHER, G.; HÜBNER, S. O.; VARGAS, G. A.; VIDOR, T. BROD, C. S. Prevalência e fatores associados à infecção pelo vírus da diarréia viral bovina na região Sul do Rio Grande do Sul. Semina: Ciências Agrárias,v. 28, n. 2, p. 269-276, 2007.

RADOSTITS, O. M.; GAY, C. C.; BLOOD, D. C.; HINCHCLIFF, K. W. Clínica Veterinária. São Paulo: Guanabara Koogan, 2002.

RAVAZZOLO, A. P.; COSTA, U. M. Retroviridae. In: FLORES, E. F (Org.) Virologia Veterinária. Santa Maria: Ed. da UFSM, 2012.

RIDPATH, J. F.; BAUERMANN, F. V.; FLORES, E. F. Flaviviridae. In: FLORES, E. F (Org.) Virologia Veterinária. Santa Maria: Ed. da UFSM, 2012.

ROCHA, M. A.; GOUVEIA, A. M. G., LOBATO, Z. I. P.; LEITE, R. C. Pesquisa de anticorpos para IBR em amostragem de demanda no Estado de Minas Gerais, 1990-1999. Arquivo Brasileiro de Medicina Veterinária e Zootecnia, v. 53, n. 6, p. 645-647, 2001.

ROIZMANN, B.; PELLETT, P. E. The family Herpesviridae, a brief introduction. In: KNIPE, M.D. \& HOWLEY, P.M. Field's Virology. Philadelphia: Lippincott Williams and Wilkins, 2007, p. 2480-2497.

SCHUCH, L. F. D. Diarréia Viral Bovina. In: CORREA, F. R.; SCHIELD, A. L.; MENDEZ, M. D. C.; LEMOS, R. A. A. Doenças de Ruminantes e Equinos. São Paulo: Varela, 2001.

TAKIUCHI, E.; MÉDICI, K. C.; ALFIERI, A. F.; ALFIERI, A. A. Bovine herpesvirus type 1 abortions detected by a semi-nested PCR in Brazilian cattle herds. Research in Veterinary Science, $v$. 79, p. 85-88, 2005.

THIRY, J.; WIDÉN, F.; GRÉGOIRE, F.; LINDEN, A.; BELÁK, S; THIRY, E. Isolation and characterisation of a ruminant alphaherpesvirus closely related to bovine herpesvirus 1 in a free-ranging red deer. BioMed Central Veterinary Research, v. 3, p. 26-37, 2007. 
URBINA, A. M.; RIVEIRA, J. L. S.; CORREA, J. C. S. Rinotraquetis infecciosa bovina em hatos lecheros de la región cotzio-téjaro, Michoacán, México. Técnica Pecuária em México, v. 43 n. 1, p. 27-37, 2005.

Autor para correspondência: Matheus Piovesan, Laboratório de Virologia e Imunologia, Faculdade de Veterinária, Universidade Federal de Pelotas - CP 354 - CEP 96010-900 - Pelotas - RS - Brasil. matheuspiovesan@hotmail.com 